\title{
Breast Cancer in Pregnancy
}

\author{
Shashikala Ksheerasagar ${ }^{1}$ (1) Geeth Monnappa $^{2} \cdot$ N. Venkatesh ${ }^{3}$
}

Received: 19 December 2016/ Accepted: 6 February 2017/Published online: 10 March 2017

(C) Federation of Obstetric \& Gynecological Societies of India 2017

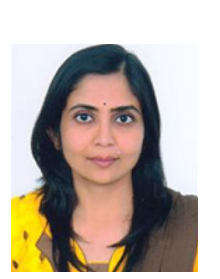

\begin{abstract}
About the Author
Shashikala Ksheerasagar is currently working as consultant $\mathrm{Ob}$ Gyn and Reproductive Medicine at Vikram Hospital, Bengaluru. She has worked with Dr Kamini Rao during her fellowship in Reproductive medicine from the Rajiv Gandhi University of Health Sciences, Bengaluru. She is a Member of the RCOG since 2008 and has presented papers and posters in National and International Conferences. She has also participated as Faculty in workshops and scientific programmes conducted by Bangalore Society of Obstetrics and Gynecology and other societies.
\end{abstract}

Shashikala Ksheerasagar, Consultant OBGYN and Reproductive Medicine, Vikram Hospital, Millers Road, Bengaluru, 560052; Geeth Monnappa, Consultant OBGYN, Vikram Hospital, Millers Road, Bengaluru, 560052; N. Venkatesh, Senior Consultant and Head, Department of Obstetrics and Gynecology, Vikram Hospital, Millers Road, Bengaluru 560085.

Shashikala Ksheerasagar

ksheerasagar_s@yahoo.com

1 House No 87, 6th Main, 4th Block, 3rd Stage, Banashankari, 2nd Phase (Near Giri Nagar Police Station), Bengaluru 560085, India

2 B 1104, Mantri Greens, No 1, Sampige Road, Malleshwarum, Bengaluru 560003, India

3 \# 376, 43rd Cross Road, 9th Main, 5th Block, Jayanagar, Bengaluru 560041, India

\section{Introduction}

The incidence of breast cancer which is first diagnosed in pregnancy is rather uncommon. This is a case report of a 27-year-old woman diagnosed with breast cancer in her second trimester. A multidisciplinary approach involving the clinical oncologist helped us manage the pregnancy and term delivery of the fetus without complications, despite leucopenia secondary to neoadjuvant chemotherapy. Use of G-CSF to improve the leukocyte count is highlighted.

\section{Case Report}

A 27-year-old, second gravida with previous history of cesarean section presented with lump in the left breast in 25 th week of pregnancy. On examination, the swelling was 


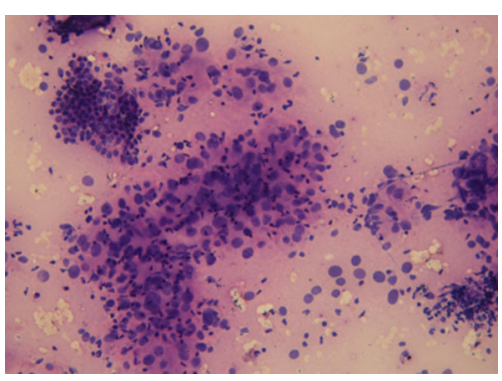

Fig. 1 FNAC smear H\&E 10X

seen in the upper outer quadrant of left breast measuring $7 \times 8 \mathrm{~cm}$, mobile, hard in consistency, non-tender, not associated with any nipple discharge. Skin, areola and nipple were unremarkable. No axillary lymph nodes were palpable. There was no history of breast cancer in her family.

On high-resolution sonography of both breasts, a welldefined complex cystic focus measuring $49 \times 39 \times 48 \mathrm{~mm}$ was seen in the left breast outer upper quadrant (1-3 "O" clock position) with peripheral vascularity. There were intraluminal echoes with vascularity. No other focal lesions were seen and there was no axillary lymphadenopathy (Fig. 1).

Fine-needle aspiration cytology showed ductal cells in loosely cohesive clusters showing nuclear pleomorphism, nuclear overlapping, coarse chromatin and conspicuous nucleoli with increased mitosis in cells with atypical mitotic figures. The background showed hemorrhage and chronic inflammatory cell infiltrate along with cyst macrophages. Impression was a high-grade infiltrating carcinoma.

Ultrasound-guided core biopsy from left breast mass was consistent with invasive ductal carcinoma grade 3 admixed with dense inflammation. Immunohistochemistry revealed the tumor to be estrogen receptor(ER)-negative, progesterone receptor (PgR)-positive, Her-2/neu-negative.

Ultrasound scan of the abdomen and pelvis was done to rule out metastasis.

Decision for neoadjuvant chemotherapy was taken; psycho-oncology counseling was done, and systemic chemotherapy was started on the 27th week of gestation with adriamycin $90 \mathrm{mg}+$ cyclophosphamide $900 \mathrm{mg}$ along with adequate intravenous hydration and supportive care. Total of three cycles of chemotherapy 3 weeks apart were given.

\section{Antepartum Monitoring}

Once the chemotherapy was started, weekly CBC was done to monitor anemia and leukopenia.

Prior to each chemotherapy, CBC, serum Creatinine and liver enzymes were repeated. Fetal growth was monitored biweekly, and there was no fetal growth restriction. Patient tolerated chemotherapy well. Few episodes of loose stools were managed with probiotics and antibiotics. Her blood sugars and blood pressure were found to be normal throughout the pregnancy. Antenatal corticosteroids to prevent neonatal morbidity in the event of a preterm delivery were administered at 30 -week gestation, prior to the second course of chemotherapy.

\section{Labor Management}

Patient presented 2 weeks following the third cycle of chemotherapy with leaking per vaginum at 37-week gestation and in early labor. At admission, her $\mathrm{Hb}$ was $8.7 \mathrm{~g} / \mathrm{dl}$, total WBC count (TC) was 1800 cumm and platelets were $3,60,000$. Her coagulation profile was normal. Admission CTG was reassuring. Option of trial of labor was refused by the patient. Decision for an emergency cesarean section was taken after explaining the risks of surgery and postsurgical infection. Inj Granulocyte-colony stimulating factor (GCSF) 300 mcg was given subcutaneously prior to the surgery. Under broad-spectrum antibiotic cover with ceftriaxone, tazobactum and metronidazole, cesarean section under spinal anesthesia was performed, and a live female baby of $2.8 \mathrm{~kg}$ with good APGAR was delivered. Intraoperative period was uneventful. Patient was kept in isolation with strict aseptic measures postoperatively. Lactation suppression with cabergoline was given due to recent exposure to chemotherapeutic drugs and the possibility of bone marrow suppression in the baby. She received a packed cell transfusion and the second injection of G-CSF on the first postoperative day. Her TC on the third postoperative day was $6270 \mathrm{cumm}$, and $\mathrm{Hb}$ was $8.3 \mathrm{~g} / \mathrm{dl}$. There was no wound infection, and patient was discharged with advice to continue oral antibiotics for 5 days, hematinics, multivitamins and analgesics. Patient was reviewed after a week, and CBC was in the normal range. Patient is due for mastectomy in 3 weeks time from the time of discharge.

\section{Discussion}

Breast cancer is the most common cancer, accounting for $2.5-32 \%$ of all female cancers in India, and has replaced carcinoma cervix as the leading cause of cancer [1]. Its incidence in younger age groups is on the rise and it is one of the most common cancers during pregnancy along with melanoma and cervical cancer. Pregnancy-associated breast cancer $(\mathrm{PABC})$ defined as breast cancer occurring during pregnancy or within first year after delivery is relatively rare with an incidence of 1 in 3000 [2]. The diagnosis is almost always delayed because of gestational 
physiological alterations in breast and occurrence at younger age. A delay of one month in diagnosis translates into a $0.9 \%$ increase in the odds of lymph node metastasis [3]. The option of termination of pregnancy should be discussed when carcinoma of breast is diagnosed in the first trimester. However, The National Comprehensive Cancer Network guideline does not recommend medical abortion for pregnancy-associated breast cancer, especially for women with early breast cancer [4]. The European society for medical oncology also considers that as evidence about any difference in prognosis between pregnant and nonpregnant women with breast cancer is lacking, it does not recommend pregnancy termination in that setting, regardless of the ER status of the tumor [5]. During the second and third trimesters, breast cancer is managed with mastectomy followed by chemotherapy. Anthracyclines and cyclophosphamides can be given safely; data on the use of taxanes are limited [6]. Neoadjuvant chemotherapy before surgery to allow tumor downstaging and to facilitate surgery is another alternative. For low-risk tumors, mastectomy will suffice as there is no indication for chemotherapy. Radiotherapy, targeted therapies and endocrine treatments are deferred till after delivery [7].

\section{Effect of Pregnancy on the Disease}

Pregnancy itself does not appear to worsen the prognosis for breast cancer in women diagnosed during pregnancy compared with non-pregnant controls matched for age and stage.

However, as pregnancy-associated breast cancer occurs in a younger population with a higher risk of metastasis, high-grade tumors and estrogen receptor-negative tumors, these women are expected to have an inferior prognosis [8].

\section{Effect of the Disease on Pregnancy}

Breast cancer does not alter the progression of pregnancy or the mode of delivery. If early delivery is necessary for maternal indication, consideration of corticosteroids for fetal lung maturation is appropriate. Birth should be planned more than 2-3 weeks after the last chemotherapy session to allow maternal bone marrow recovery and to minimize problems associated with neutropenia.

The ability to breastfeed depends on the surgery and whether the major ducts have been excised.
Breastfeeding while on chemotherapy is not advised, as the drugs cross into breast milk and may cause neonatal leucopenia with an increased risk of infection. There should be a gap of 14 days or more from the last chemotherapy session to the start of breastfeeding to allow drug clearance from breast milk.

\section{Conclusion}

Although pregnancy is not considered as the ideal time for breast examination, any lump diagnosed for the first time in pregnancy needs immediate attention. Sonomammogram with FNAC/biopsy with immunohistochemistry is important to clinch the diagnosis. A multidisciplinary approach, broad-spectrum antibiotics and use of G-CSF to improve the WBC count helped us manage the delivery and the postoperative period uneventfully.

\section{Compliance with Ethical Standards}

Conflict of interest The authors declare that there is no conflict of interest regarding the publication of this paper, and they have not received any grant.

Informed Consent Informed consent was obtained from the patient for presentation of the case report.

\section{References}

1. Gupta S. Breast cancer: Indian experience, data, and evidence. South Asian J Cancer. 2016;5:85-6.

2. Navrozoglou I, Vrekousis T, Kontostolis E, et al. Breast cancer during pregnancy: a mini-review. Eur J Surg Oncol. 2008;34:837-43.

3. Raphael J, Trudeau ME, Chan K. Outcome of patient with pregnancy during or after breast cancer: a review of recent literature. Curr Oncol. 2015;22(Suppl 1):S8-18.

4. National Comprehensive Cancer Network (NCCN) Clinical Practice guidelines in Oncology; Breast Cancer. Fort Washington PA: NCCN; 2014 Ver 32014, Dec 22, 2014.

5. Peccatori FA, Azim HA, Jr, Orecchia R, et al. on behalf of the ESMO. ESMO Clinical Practice guidelines for diagnosis and followup. Ann Oncol 2013;24(Suppl 6): VI 160-70.

6. Pentheroudakis R, Orecchia R, Hockstra H J, et al. ESMO Clinical Practice guidelines for diagnosis, treatment \& followup. Ann Oncol, 2010; 21(Suppl 5): V 266-73.

7. Litton JK. Curr Treat Options Oncol. 2012;13:137-45.

8. Green-top Guideline No. 12. (2011) Pregnancy and breast cancer. www.rcog.org.uk. 